\title{
A FUNÇÃO SOCIAL DA PROPRIEDADE SOB O PARADIGMA DO EQUILÍBRIO AMBIENTAL COMO DIREITO FUNDAMENTAL
}

\author{
Luís Carlos Gehrke ${ }^{1}$ \\ Bibiana Maria Wrasse Abreu ${ }^{2}$
}

\begin{abstract}
Resumo
Uma nova conduta de proteção ambiental é uma necessidade urgente nos dias atuais. Em face da evolução do direito a posse, criou-se a função social da mesma, que em tempos de tecnologias avançadas e grandes descuidos ambientais, evoluiu se transformando em função socioambiental. Não é contestado que o meio ambiente equilibrado é peça fundamental para a vida digna da população, sendo necessário medidas de prevenção contra depredações. Neste viés, o legislador incluiu a obrigação de preservá-lo no rol dos direitos fundamentais, a fim de tutelar a saúde das gerações atuais e seguintes.

Palavras-Chave: Função Social da Propriedade; Equilíbrio Ambiental; Direito Fundamental.
\end{abstract}

\section{I - INTRODUÇÃO}

Ao decorrer dos tempos, o direito a posse passou por mutações importantes. Inicialmente, o direito à propriedade era absoluto; após, começou a se falar na função social da propriedade, e nos dias atuais, a posse perpassa uma visão sócio ambiental, frente a necessidade de uma proteção ambiental mais intensa, uma vez que é requisito básico para uma vida digna.

Entretanto, em tempos de altas descobertas tecnológicas, o treinamento para uma cultura verde é vista por muitos como um retrocesso, o que dificulta a implementação de medidas de prevenção.

Nesse passo, considerando o risco iminente, bem como a grande resistência principalmente de alguns grupos -, o legislador inseriu a função social da propriedade e a proteção ao meio ambiente como vetores na Carta Magna vigente, com força de normativa fundamental, a fim de assegurar para as futuras gerações a vida digna, princípio basilar da Constituição Brasileira.

\footnotetext{
${ }^{1}$ Professor de Direito Civil e Coordenador do Núcleo Permanente de Prática Jurídica da Faculdade Metodista de Santa Maria - FAMES. Especialista em Processo Civil pela Universidade Regional da Campanha - Campus/São Gabriel. Mestre em Integração Latino-Americana (MILA) pela Universidade Federal de Santa Maria/RS. Advogado atuante.

${ }^{2}$ Acadêmica do Curso de Direito da Faculdade Metodista de Santa Maria - FAMES. Funcionária Pública do Administrativo Municipal de Faxinal do Soturno. Endereço Eletrônico: bibiwrasse@ yahoo.com.br.
} 


\section{II - A FUNÇÃo SÓCIO AMBIENTAL DA PROPRIEDADE E AS MEDIDAS DE (EFETIVA) PROTEÇÃO}

O debate acerca da questão relativa a posse, sob viés social, passa, necessariamente, pela análise no que diz respeito a migração do campo para a(s) cidade(s), haja vista que o instituto da posse, há muito, deixou de ser uma questão meramente idealista, passando o legislador a conferir-lhe um caráter eminentemente pragmático, vinculado às questões sociais.

Neste viés, a transição do feudalismo para o capitalismo - marco divisório na história, com produção baseada na venda da força do trabalho -, modificou a sociedade, culminando com a Revolução Industrial, no qual as cidades passaram a ser destino de milhares de pessoas, provocando o despovoamento gradativo do campo, especialmente em países em desenvolvimento, cuja população e a economia tinha como lastro o campo.

Sob essa ótica e como é notório, os países latino-americanos e, em especial, os mercosulistas, desde o seu descobrimento, sofreram alta influência de seus países colonizadores, passando a ser palco de inúmeros movimentos migratórios, afetando a sociedade como um todo.

Desta forma, a sociedade evoluiu, seja pela influência de ideias modernas, seja pela concepção mais voltada ao social, como reminiscências, ainda do iluminismo francês, precursor dos direitos humanos, evidenciando-se assim propostas reflexivas acerca do respeito aos direitos humanos e do princípio da dignidade da pessoa humana.

Nesse contexto, passo a passo, a universalização dos direitos humanos ganha força e, sob o prisma jurídico, infere-se que a primazia da pessoa, fundada na dignidade da pessoa humana, é a resposta às questões de forte segregação social, existente nas cidades e no campo, guardando ambas, uma estrutura fragmentada e segmentada, no qual o positivismo jurídico mantém-se emblemático, principalmente quando o assunto é a propriedade privada.

Em razão disso, a questão antagônica que se estabelece entre a posse e a propriedade privada ganha cada vez mais espaço. De um lado, sobreleva-se a importância da posse, não simplesmente como meio de manifestação da propriedade, 
mas como direito legítimo e fundamental de moradia, cumprindo assim sua efetiva função social. Por outro lado, os argumentos baseiam-se no respeito às leis e no Estado Democrático de Direito, no qual todo cidadão tem assegurado o exercício do legítimo direito de defesa da propriedade, bem como de seu uso privado.

No Brasil, em particular, o processo migratório foi decisivo para a mudança do paradigma constitucional, haja vista que a Constituição Federal de 1988 propôs a construção de um Estado Democrático de Direito, destinado a assegurar o exercício dos direitos sociais e individuais, a liberdade, a segurança, o bem-estar, o desenvolvimento, a igualdade e a justiça, os quais são considerados como valores supremos de uma sociedade fraterna, pluralista e sem preconceitos, rompendo com o preceito autoritário militar, vigente na constituição anterior.

Tais propósitos incentivam discussões sobre a construção de uma sociedade livre, justa e solidária, que busca o desenvolvimento nacional, a erradicação da pobreza e da marginalidade, reduzindo as desigualdades sociais e regionais. São incluídos temas como o bem estar de todos, sem preconceitos étnicos, de gênero, de idade e quaisquer outras formas de discriminação, elegendo-se o valor da dignidade da pessoa humana como essencial, ressaltando o sentido da cidadania, bem como dos direitos e das garantias fundamentais, oferecendo suporte axiológico a todo sistema jurídico brasileiro.

À luz desta concepção, tem-se que o Estado Democrático de Direito guarda, na verdade, uma gênese mais voltada à dignidade da pessoa humana. Simboliza um superprincípio constitucional, tendo a função social da propriedade como esteio, haja vista que é um instituto que visa a fomentar o acesso a um dos bens que compõem o núcleo da dignidade humana, qual seja a moradia, cada vez mais precária e indigna.

Neste viés, com o passar do tempo, a propriedade passou a exercer uma função social, e não apenas individual, devendo ser exercida a posse, sempre em conformidade com as normas legais e administrativas, com o fim de disciplinar o convívio harmonioso de seus habitantes, tanto na propriedade urbana, como rural, o que justifica sua inclusão como preceito constitucional, como meio de propiciar e alcançar a dignidade da pessoa humana (SIRVINSKAS, 2009).

Registre-se que nenhum princípio supera o da dignidade humana, mormente quando esta é o pressuposto da ideia de justiça humana, independentemente de 
merecimento pessoal ou social. É a vertente contemporânea do direito do pós-guerra, ocasião em que houve uma aceleração do movimento migratório internacional sendo que o Brasil não fugiu a essa tendência mundial.

Entretanto, a partir do momento em que o foco interpretativo consolidou-se com a nova Constituição Federal de 1988, a temática passou a ganhar novos horizontes, especialmente no que tange à moradia, positivando-se a partir da Emenda Constitucional $n^{\circ} 26$, que permitiu ao legislador pátrio elevar a moradia a direito fundamental, somando-se aos demais direitos já previstos no artigo $6^{\circ}$ da Carta Maior, ratificando o artigo $7^{\circ}$ (IV) da mesma norma legal, no qual já havia o status pretendido.

Sob essa abordagem, o Brasil passou a conferir à posse e à propriedade uma enorme relevância, na medida em que atende a uma situação de alta importância para as pessoas, haja vista que a movimentação das pessoas constitui contrapartida da reestruturação territorial, não apenas limitada ao município ou Estado, mas no país como um todo, reflexo de uma dogmática econômico-produtivo em escala global.

Desta forma, a posse vem assumindo papel de destaque nas relações internacionais, especialmente em função do aspecto social, onde está mais presente do que na própria propriedade, já que esta, mesmo sem uso, não perde seu status, face ao princípio da perpetuidade, enquanto aquela revela necessidades prementes: a moradia e a posse direta. Por conta disso, o processo migratório campo-cidade, associado a forte expansão espacial da agricultura, vinculado à extrema concentração fundiária, fez com que novos caminhos fossem almejados pela população, provocando, não raras vezes, invasão de áreas urbanas e/ou uso impróprio de áreas que deveriam ser preservadas, tais como encostas de morros, beira de córregos, locais onde a dignidade das pessoas inexiste.

Contudo, os problemas sociais decorrentes desta migração desenfreada e maciça das pessoas, sem planejamento e preparação, provocam uma verdadeira batalha estrutural diante dos efeitos perversos para a sociedade, especialmente para aquelas em desenvolvimento. Talvez pela própria estratégia globalizada de estímulo às pessoas a buscarem e a almejarem oportunidades e padrões de vida além fronteiras que, muitas vezes, não se revela nada benéfico, eis que o preço alto é pago pelas futuras gerações.

Sob esta ótica, a função social da posse traz consigo, em sua própria definição, relevantes consequências, pois dela depreende-se que todo cidadão tem direito ao uso 
dos bens e à apropriação individual através da posse, de modo a atender suas necessidades individuais, bem como para oferecer vantagens ao bem comum. Essa importância vem ditada, não apenas pelo contato físico do homem com a terra, mas, também, pela ocupação produtiva e proveitosa do espaço, através do trabalho, e de acordo com as necessidades sociais e pessoais, favorecendo a toda a sociedade, surgindo daí uma visão mais ampla sobre o tema.

Entretanto, o processo de incentivação governamental no sentido da urbanização acelerada, induzidas por uma ideia de que nas cidades haveriam maiores ofertas, tanto de trabalho como de condição de vida, tornou-as cada vez mais inchadas, muitas vezes sem estrutura adequada, despovoando gradativamente o campo, surgindo, a partir daí, problemas de toda ordem, cujos reflexos maiores dar-se-ão para as próximas gerações.

Neste diapasão, uma das grandes questões que surge é justamente o desenvolvimento sustentável - consubstanciado na ideia de atender as necessidades presentes sem comprometer as necessidades/possibilidades das gerações futuras -, na medida em que o futuro depende da avaliação dos riscos de decisões tomadas no presente. Com base nisto, o legislador consagrou a responsabilidade civil por danos causados ao meio ambiente, como objetiva e solidária, o que denota que não é necessária culpa subjetiva para a obrigação de reparar danos ambientais (FIORILLO, 2009).

Menos mal que hoje a sociedade já está se conscientizando - mesmo que tardiamente, e para isso se presta a discussão em momentos como este -, para tentar dimensionar as consequências deste desenvolvimento incontrolável, não apenas baseado numa sociedade industrial, onde a lógica do mercado não possibilita ao consumidor pensar e fazer eventuais questionamentos, surgindo o chamado agronegócio, ou seja, uma agricultura cada vez mais tecnificada, inserida no contexto de uma escala industrial.

Contudo, para que o agronegócio possa atingir a sustentabilidade, faz-se necessário que se alcance a soberania alimentar e o acesso a alimentos para a população (segurança alimentar), na medida em que voltado para o mercado de exportação, não atinge ao mercado interno - que é abastecido pelos pequenos produtores, que assim cumprem com a segurança alimentar, que se obtém pelas políticas públicas voltadas ao 
meio rural, especialmente atendendo a dignidade da pessoa humana e a soberania alimentar -, bem como não garante a soberania alimentar.

A par disso, políticas públicas devem ser voltadas ao meio rural, seja no âmbito de políticas fundiárias - atendendo a função social da posse e da propriedade -, ou políticas agrícolas - com temáticas atreladas ao preço, crédito, subsídios, assistência técnica, seguro agrícola, preocupação com recursos naturais e ambientais, etc, mas para isso, é imprescindível que esteja atrelada ao atendimento a função socioambiental da propriedade.

Neste sentido, a função socioambiental da propriedade rural somente é cumprida quando atende todos os critérios expostos no artigo $186^{3}$ da Constituição Federal vigente, através de um aproveitamento racional e adequado, o que implica, ainda de acordo com o mesmo autor, em condutas positivas e negativas. Assim, ao se falar em condutas positivas, tem-se como tal a averbação de reserva legal florestal ou recomposição de áreas degradadas e, por outro lado, tem-se como atos negativos a não poluição, o não desmatamento e a não degradação (OLIVEIRA, 2011).

Ainda neste diapasão, da tentativa de se impor ao proprietário rural e ao produtor rural, o atendimento da função social da propriedade rural, tornou-se indispensável a aplicação do Princípio do Poluidor-Pagador, no qual o responsável por determinada degradação ou poluição é penalizado de forma a recuperar ou indenizar pelo dano causado (TRENNEPOHL, 2010). Para o autor, busca-se compensar a degradação (chamada por alguns doutrinadores de externalidades negativas) haja vista o dano ser coletivo e o lucro recebido pelo produtor, privado.

Entretanto, o grande entrave é que hoje o agronegócio brasileiro, está marcado por uma profunda acumulação de capital em nível internacional (globalização) o que fez com que a agricultura esteja voltada para atender aos interesses internacionais, ignorando completamente os interesses dos povos a suas soberanias alimentares, tudo pautado por tecnologia, mas que ao mesmo tempo em que diminuem o ciclo natural e

\footnotetext{
3 Art. 186. A função social é cumprida quando a propriedade rural atende, simultaneamente, segundo critérios e graus de exigência estabelecidos em lei, aos seguintes requisitos:

I - aproveitamento racional e adequado;

II - utilização adequada dos recursos naturais disponíveis e preservação do meio ambiente;

III - observância das disposições que regulam as relações de trabalho;

IV - exploração que favoreça o bem-estar dos proprietários e dos trabalhadores
} 
III SEMINÁRID ECDLDGIA

Princípio 15 - De modo a proteger o meio ambiente, o princípio da precaução deve ser amplamente observado pelos Estados, de acordo com suas capacidades. Quando houver ameaça de danos sérios ou irreversíveis, a ausência de absoluta certeza científica não deve ser utilizada com a razão para postergar medidas eficazes e economicamente viáveis para prevenir a degradação ambiental.

Princípio 16- Tendo em vista que o poluidor deve, em princípio, arcar com o custo decorrente da poluição, as autoridades nacionais devem procurar promover a internalização dos custos ambientais e o uso de instrumentos econômicos, levando na devida conta o interesse público, sem distorcer o comércio e os investimentos internacionais (CASTRO, 2006, p.32).

A partir disso, mais do que nunca deve-se buscar a efetividade quanto a função social da terra a partir da posse sob o viés do meio ambiente. O que está sendo feito sobre isso?

Assim, o pensar ético ganha espaço. Tanto no âmbito do direito agrário como do direito ambiental, que não devem estar submetidos à lógica do mercado (auferindo lucros a curto prazo, desmantelando biomas, trazendo sérias consequências às relações de trabalho - escravo, infantil -, comprometendo ecossistemas e causando danos irreparáveis às gerações futuras).

Destaque-se que, nos dias atuais já é possível desenvolver uma agricultura ecologicamente equilibrada e economicamente viável, através da produção sem agrotóxicos. Ormond, Paula, Filho e Rocha debatem a respeito da rentabilidade do cultivo verde:

\footnotetext{
Os preços pagos aos produtores pelos produtos orgânicos têm sido bastante atraentes, o que poderia compensar o uso mais intenso de mão-de-obra, uma produtividade provavelmente menor no início da produção e os custos de certificação, fatores muitas vezes mencionados pelos produtores. Já a menor produtividade das lavouras não tem se mostrado uma verdade absoluta, pois já foram registrados casos de manutenção ou mesmo de aumento do rendimento físico da lavoura desde o início da utilização do manejo orgânico (ORMOND; PAULA; FILHO; ROCHA, 2002, p. 16).
}

Neste viés, vê-se que não há necessidade de mais áreas para produção agrícola, nem mesmo da utilização desenfreada de agrotóxicos, pois se o produtor rural souber utilizar de maneira inteligente sua área, estará cumprindo com a função socioambiental da mesma, além de, possivelmente, auferindo uma cultura mais lucrativa. 


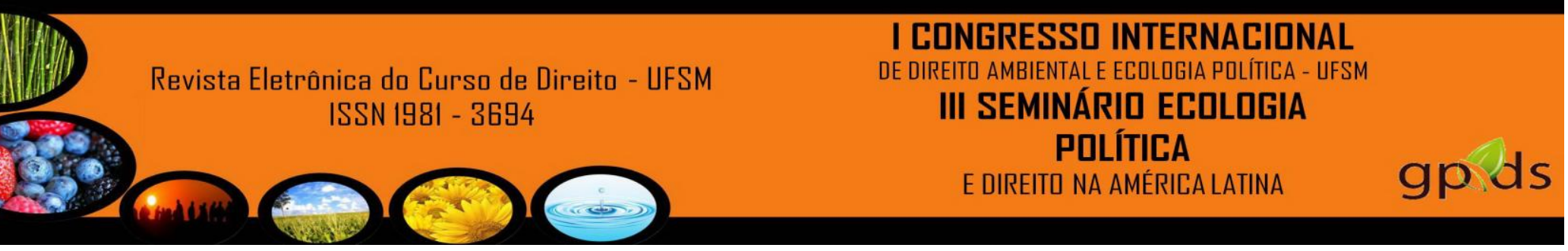

E isso justamente é o que prevê a doutrina de Marchesan, Steigleder e Cappelli, como forma de exercício regular de um direito atinente a propriedade, não mais exercido unicamente à vontade do proprietário, devendo esta obedecer a função socioambiental da propriedade, exercida com limites, de acordo com as necessidades sociais e de preservação ambiental (MARCHESAN; STEIGLEDER; CAPPELLI, 2004).

Por isso, e já finalizando, cabe desde já ao acadêmico e futuro operador do direito, ser um cientista social com foco jurista, na medida em que jamais deve abdicar das premissas fundamentais e os princípios basilares do direito: como a dignidade da pessoa humana e os direitos fundamentais do homem, tudo consubstanciado na ética, pois o homem está inserido na natureza e o ambiente ecologicamente equilibrado, mas não é dono dela.

\section{III - CONSIDERAÇÕES FINAIS}

Diante do atual estudo, tem-se claro que a função socioambiental da propriedade é necessária para a preservação da vida digna das futuras gerações, hoje inserido dentre o rol dos direito fundamentais.

No âmbito da propriedade rural, vê-se que demonstra inteligência o produtor que utiliza-se de maneiras ecologicamente corretas para a produção e tal atitude, além de contribuir para um meio ambiente equilibrado, muitas vezes tem demonstrado ser economicamente mais vantajoso, revelando-se um retrocesso o uso indiscriminado de agrotóxicos e pesticidas, altamente prejudiciais à saúde humana e ambiental.

\section{IV - REFERÊNCIAS BIBLIOGRÁFICAS}

BRASIL Constituição (1988). Constituição da República Federativa do Brasil. Brasília - DF: Senado, 2012.

CASTRO, João Marcos Adede Y. Tutela Civil do Meio Ambiente. Porto Alegre: Sergio Antonio Fabris Editor, 2006.

FIORILLO, Celso Antônio Pacheco. Curso de Direito Ambiental Brasileiro. São Paulo: Saraiva, 2009. 


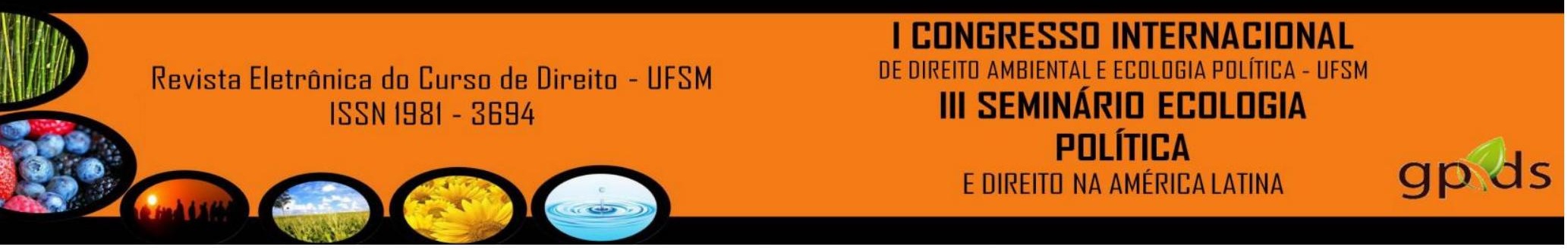

MARCHESAN, Ana Maria Moreira; STEIGLEDER, Anelise Monteiro; CAPPELLI, Sílvia. Direito Ambiental. Porto Alegre: Editora Verbo Jurídico, 2004.

MEZZOMO, M.C.; COELHO, J.L.F. A Função Social da Propriedade nos Contratos Agrários. Jus Navegandi, a.7, n.66, 2003. Disponível em:

<http://jus2.uol.com.br/doutrina/texto/asp>. Acesso em: 28 jun. 2008.

MEZZOMO, M.C. A Função Social da Propriedade nos Contratos Agrários.

Disponível em: <http://www.ufsm.br/direito/artigos/agrario/funcao-social.htm>. Acesso em 22 jul. 2008.

OLIVEIRA, Fabiano Melo Gonçalves de. Direito Ambiental. São Paulo: Editora Revista dos Tribunais, 2011.

ORMOND, José Geraldo Pacheco; PAULA, Sergio Roberto Lima de; FILHO, Paulo Favaret; ROCHA, Luciana Thibau M. da. Agricultura Orgânica: Quando o Passado é Futuro. Disponível em: < http://sma.visie.com.br/wp-content/uploads/cea/JoseO.pdf $>$. Acesso em: 28 ago 2012.

SIRVINSKAS, Luis Paulo. Manual de Direito Ambiental. São Paulo: Saraiva, 2009.

TRENNEPOHL, Terence Dorneles. Manual de Direito Ambiental. São Paulo: Saraiva, 2010. 